Research Paper

\title{
Association of the rs7395662 SNP in the MADD-FOLHI and Several Environmental Factors with Serum Lipid Levels in the Mulao and Han Populations
}

\author{
Ke-Ke Huang ${ }^{1}$, Rui-Xing Yin ${ }^{\circledR}{ }^{凶}$, Xiao-Na Zeng ${ }^{1}$, Ping Huang ${ }^{1}$, Quan-Zhen Lin ${ }^{1}$, Jian Wu 1, Tao Guo ${ }^{1}$,
} Wei Wang ${ }^{1}$, De-Zhai Yang ${ }^{2}$, Wei-Xiong Lin ${ }^{2}$

1. Department of Cardiology, Institute of Cardiovascular Diseases, the First Affiliated Hospital, Guangxi Medical University, 22 Shuangyong Road, Nanning 530021, Guangxi, People's Republic of China

2. Department of Molecular Biology, Medical Scientific Research Center, Guangxi Medical University, 22 Shuangyong Road, Nanning 530021, Guangxi, People's Republic of China

$\square$ Corresponding author: Prof. Rui-Xing Yin, Department of Cardiology, Institute of Cardiovascular Diseases, the First Affiliated Hospital, Guangxi Medical University, 22 Shuangyong Road, Nanning 530021, Guangxi, People's Republic of China. Tel: +86-771-5326125; Fax: +86-771-5353342; e-mail: yinruixing@163.com.

(c) Ivyspring International Publisher. This is an open-access article distributed under the terms of the Creative Commons License (http://creativecommons.org/ licenses/by-nc-nd/3.0/). Reproduction is permitted for personal, noncommercial use, provided that the article is in whole, unmodified, and properly cited.

Received: 2013.04.07; Accepted: 2013.08.12; Published: 2013.09.0I

\begin{abstract}
Background: The rs7395662 single nucleotide polymorphism (SNP) in the MADD-FOLHI has been associated with serum lipid traits, but the results are inconsistent in different populations. The present study was undertaken to investigate the association of rs7395662 SNP and several environmental factors with serum lipid levels in the Guangxi Mulao and Han populations.

Method: A total of 721 subjects of Mulao and 727 subjects of Han Chinese were randomly selected from our previous stratified randomized samples. Genotyping of the SNP was performed by polymerase chain reaction and restriction fragment length polymorphism combined with gel electrophoresis, and confirmed by direct sequencing.

Results: Serum apolipoprotein (Apo) B levels were higher in Mulao than in $\mathrm{Han}(P<0.0 \mathrm{I})$. The allelic and genotypic frequencies in Han were different between males and females $(P<0.05$ for each), but there was no difference between Mulao and Han or between Mulao males and females. The levels of low-density lipoprotein cholesterol (LDL-C) and ApoB in Mulao females were different among the genotypes $(P<0.05)$, the $G$ allele carriers had higher LDL-C and ApoB levels than the $G$ allele non-carriers. The levels of total cholesterol (TC), triglyceride (TG), LDL-C and ApoB in Han males and TC, TG and high-density lipoprotein cholesterol (HDL-C) in Han females were different among the genotypes $(P<0.05-0.01)$, the subjects with $G G$ genotype in Han males had higher TC, TG, and ApoB and lower LDL-C levels than the subjects with AA or AG genotype, and the $G$ allele carriers in Han females had lower TC and HDL-C levels than the $G$ allele non-carriers. The levels of LDL-C and ApoB in Mulao females were correlated with the genotypes $(P<0.05$ for each). The levels of HDL-C and ApoAl in Han males and HDL-C in Han females were correlated with genotypes $(P<0.05-0.00 \mathrm{I})$. Serum lipid parameters were also correlated with several environmental factors in both ethnic groups $(P<0.05-0.01)$.

Conclusion: The association of rs7395662 SNP and serum lipid levels is different between the Mulao and Han populations, and between males and females in both ethnic groups.
\end{abstract}

Key words: environmental factors, $M A D D-F O L H 1$, lipid profiles, single nucleotide polymorphism.

\section{Introduction}

It is well known that coronary artery disease $(\mathrm{CAD})$ is a multifactorial chronic disease, whose morbidity and mortality remain high worldwide [1-3]. Dislipidemia has been shown to play a prominent role 
in the process of CAD and it accounts for $~ 50 \%$ of the population attributable risk of developing CAD [4]. Based upon the results of recent studies, which had demonstrated that dislipidemia is a distinct complex trait resulted from multiple environmental and genetic factors as well as their interactions [5-7]. In twin and family studies, it was surveyed that plasma lipid levels were estimated to range from $0.28-0.78$ with heritability [8]. However, the genetic architecture of serum lipid profiles is assumed to be intricate and continues to be poorly understood.

Numerous genetic variants associated with serum lipid levels have been identified in the genome-wide association studies (GWAS) in different populations [2, 5, 9-29]. On one hand, common variants at these loci collectively are estimated to explain only a small proportion of variation in each lipid trait $[14,15,27]$ and $25 \%-30 \%$ of the genetic variability in plasma lipid phenotypes [5]; on the other hand, the heritability of lipid traits may also lead to large individual effects for other rare variants [27]. Previous GWAS have also discovered a large number of novel loci that impact phenotypes of serum lipid levels [5, 14, 30-32]. One of these newly identified single nucleotide polymorphisms (SNPs) is the rs7395662 SNP in the MADD-FOLH1.

The rs7395662 SNP is located on chromosome 11 p11 in a flanking locus between MADD and FOLH1, which represents a gene desert close to the centromere with no known gene on the 500-kb flanking region [14]. The MADD-FOLH1 stands for MAP-kinase activating death domain and folate hydrolase respectively and the roles of MADD and FOLH1 in lipid metabolism are still poorly defined $[14,31]$. In light of our best knowledge, MADD encodes MAP-kinase activating death domain containing protein. This protein can modulate the tumor necrosis factor-alpha (TNF-a) and propagate the apoptotic signal. For FOLH1, we learn that a mutation in FOLH1 may be interacted with impaired absorption of dietary folates. In European population, the rs7395662 SNP in the MADD-FOLH1 has been shown that it is significant associated with high-density lipoprotein cholesterol (HDL-C) concentration [14, 33]. Exactly as patterns of linkage-disequilibrium vary between populations, the results are complicated and inconsistent across different populations $[34,35]$. In practical, there are still a large amount of variants have not been largely explored in various racial/ethnic groups, and more studies need to be carried on for further understanding about rs7395662 SNP in the MADD-FOLH1.

As a multiethnic country, China possesses 56 ethnic groups and Han nationality is the largest member in the 56 ethnic groups. Mulao nationality is one of the 55 minorities with population of 207,352 according to the fifth national census statistics of China in 2000. Ninety percent of them live in the Luocheng Mulao Autonomous Country, Guangxi Zhuang Autonomous Region, People's Republic of China. Dating back to the Jin Dynasty (AD265-420), this minority had been written down into gorgeous history in China. It is established that the Mulao population are the descendants of the ancient Baiyue tribe in south China. Besides, they are related ethnically to the neighboring ethnic groups. In a previous study, $\mathrm{Xu}$ et al. [36] showed that the genetic relationship between Mulao nationality and other minorities in Guangxi was much closer than that between Mulao and Han or Uighur nationality. Owing to a variety of lifestyles and environments in our population resident in Guangxi, the effect of genetic variation may be further modified. Since Mulao population has different lifestyles and customs, it tends to be more genetically isolated. However, whether rs7395662 SNP confer significant association with serum lipid levels remains unexplored. Thus, the aim of the present study was to detect and get insight into the association of rs7395662 SNP in the MADD-FOLH1 and several environmental factors with serum lipid traits in the Guangxi Mulao and Han populations.

\section{Materials and methods}

\section{Participants}

Participants in the present study included 721 individuals of Mulao nationality living in Luocheng Mulao Autonomous County, Guangxi Zhuang Autonomous Region, People's Republic of China. They were randomly selected from our previous stratified randomized samples [37]. The ages of the participants ranged from 15 to 86 years, with an average age of $52.31 \pm 14.50$ years. There were 336 males $(46.6 \%)$ and 385 females $(53.4 \%)$. All participants were rural agricultural workers. Meanwhile, a total of 727 Han nationality who reside in the same villages were also randomly selected from our previous stratified randomized samples. The average age of the subjects was $51.94 \pm 12.92$ years, which ranged from 15 to 84 years. There were 346 men $(47.6 \%)$ and 381 women $(52.4 \%)$. All of them were also rural agricultural workers. All study subjects were essentially healthy and had no evidence of any chronic illness, including hepatic, renal, or thyroid. The participants with a history of heart attack of myocardial infarction, stroke, congestive heart failure, diabetes or fasting blood glucose $\geq$ $7.0 \mathrm{mmol} / \mathrm{L}$ determined by glucose meter were excluded from the analyses. The participants were not taking medications known to affect serum lipid levels (lipid-lowering drugs such as statins or fibrates, beta-blockers, diuretics, or hormones). The experimental 
design was approved by the Ethics Committee of the First Affiliated Hospital Guangxi Medical University. All participants in this study provided written informed consent.

\section{Epidemiological survey}

The survey was carried out using internationally standardized methods [38]. All participants underwent a complete history, physical examination, and laboratory assessment of cardiovascular risk factors, including cigarette smoking, family history of myocardial infarction, blood pressure, presence of diabetes mellitus. Information on demographics, socioeconomic status, and lifestyle factors was collected with standardized questionnaires. The alcohol information included questions about the number of liangs (about $50 \mathrm{~g}$ ) of rice wine, corn wine, rum, beer, or liquor consumed during the preceding 12 months. Alcohol consumption was categorized into groups of grams of alcohol per day: $\leq 25$ and $>25$. Smoking status was categorized into groups of cigarettes per day: $\leq 20$ and $>20$. At the physical examination, several parameters were measured. Sitting blood pressure was measured three times with the use of a mercury sphygmomanometer after the subjects had a 5-minute rest, and the average of the three measurements was used for the level of blood pressure. Systolic blood pressure was determined by the first Korotkoff sound, and diastolic blood pressure was determined by the fifth Korotkoff sound. Body weight, to the nearest 50 grams, was measured by using a portable balance scale. Subjects were weighed without shoes and minimum of clothing. Height was measured, to the nearest $0.5 \mathrm{~cm}$, using a portable measuring device. From these two measurements body mass index (BMI, $\left.\mathrm{kg} / \mathrm{m}^{2}\right)$ was calculated.

\section{Determination of serum lipid levels}

Venous blood samples were collected after an overnight (at least 12 hours) fast. A part of the sample $(2 \mathrm{~mL})$ was collected into glass tubes and allowed to clot at room temperature, and used to determine serum lipid levels. Another part of the sample $(3 \mathrm{~mL})$ was transferred to tubes with anticoagulate solution $(4.80 \mathrm{~g} / \mathrm{L}$ citric acid, $14.70 \mathrm{~g} / \mathrm{L}$ glucose, and $13.20 \mathrm{~g} / \mathrm{L}$ tri-sodium citrate) and used to extract DNA. Serum total cholesterol (TC), triglyceride (TG), HDL-C, and low-density lipoprotein cholesterol (LDL-C) levels in the samples were measured according to standard enzymatic methods. Serum apolipoprotein (Apo) AI and $A p o B$ levels were determined by the immunoturbidimetric immunoassay. All determinations were performed with an autoanalyzer (Type 7170A; Hitachi Ltd, Tokyo, Japan) in the Clinical Science Experiment Center of the First Affiliated Hospital, Guangxi Med- ical University [6, 7].

\section{DNA preparation and genotyping}

Genomic DNA was isolated from peripheral blood leukocytes using the phenol-chloroform method [39, 40]. Genotyping of the rs7395662 SNP was performed by polymerase chain reaction and restriction fragment length polymorphism (PCR-RFLP). PCR amplification was performed using 5'-ACCCCTATGTTGAACCCT-3' and 5'-AGCATGCAGGGAAAATCATTTATTA-3' (Sangon, Shanghai, People's Republic of China) as the forward and reverse primer pairs; respectively. Each amplification reaction was performed using $100 \mathrm{ng}$ (2 $\mu \mathrm{L}$ ) of genomic DNA in $25 \mu \mathrm{L}$ of reaction mixture consisting of $1.0 \mu \mathrm{L}$ of each primer $(10 \mu \mathrm{mol} / \mathrm{L}), 12.5$ $\mu \mathrm{L} 2 \times$ Taq PCRMasterMix (constituent: 0.1 U Taq polymerase $/ \mu \mathrm{L}, 500 \mu \mathrm{M}$ dNTP each, $20 \mathrm{mM}$ Tris- $\mathrm{HCl}$, $\mathrm{pH}$ 8.3, $100 \mathrm{mM} \mathrm{KCL}, 3 \mathrm{mM} \mathrm{MgCl}$, and stabilizers), and nuclease-free water $8.5 \mu \mathrm{L}$. After initial denaturizing at $95{ }^{\circ} \mathrm{C}$ for $5 \mathrm{~min}$, the reaction mixture was subjected to 35 cycles of denaturation at $95^{\circ} \mathrm{C}$ at $45 \mathrm{~s}$, annealing at $59^{\circ} \mathrm{C}$ for $45 \mathrm{~s}$ and extension $45 \mathrm{~s}$ at $72^{\circ} \mathrm{C}$, followed by a final $5 \mathrm{~min}$ extension at $72{ }^{\circ} \mathrm{C}$. After electrophoresis on a $2 \%$ agarose gel with $0.5 \mu \mathrm{g} / \mathrm{mL}$ ethidium-bromide, the amplification products were visualized under ultraviolet light. Then $2.5 \mathrm{U}$ of Hin1II restriction enzyme, $9 \mu \mathrm{L}$ nuclease-free water and $1 \mu \mathrm{L}$ of $10 \times$ buffer solution were added directly to the PCR products $(5 \mu \mathrm{L})$ and digested at $37^{\circ} \mathrm{C}$ overnight. After restriction enzyme digestion of the amplified DNA, genotypes were identified by electrophoresis on $2.5 \%$ agarose gel and visualized with ethidium-bromide staining ultraviolet illumination. Genotypes were scored by an experienced reader blinded to epidemiological data and serum lipid levels.

\section{DNA sequencing}

Six samples (AA, AG and GG genotypes in two; respectively) detected by PCR-RFLP were also confirmed by direct sequencing. The PCR products were purified by low melting point gel electrophoresis and phenol extraction, and then the DNA sequences were analyzed in Shanghai Sangon Biological Engineering Technology \& Services Co., Ltd., People's Republic of China.

\section{Diagnostic criteria}

The normal values of serum TC, TG, HDL-C, LDL-C, ApoAI, ApoB levels and the ratio of ApoAI to ApoB in our Clinical Science Experiment Center were 3.10-5.17, $0.56-1.70, \quad 1.16-1.42, \quad 2.70-3.10 \mathrm{mmol} / \mathrm{L}$, 1.20-1.60, 0.80-1.05 g/L, and 1.00-2.50; respectively [41]. The individuals with TC $>5.17 \mathrm{mmol} / \mathrm{L}$, and/or TG $>1.70 \mathrm{mmol} / \mathrm{L}$ were defined as hyperlipidemic [6, 
7 , 37]. Hypertension was diagnosed according to the criteria of 1999 World Health Organization-International Society of Hypertension Guidelines for the management of hypertension. Hypertension was defined as an average systolic blood pressure $(\mathrm{SBP}) \geq 140 \mathrm{~mm} \mathrm{Hg}$, an average diastolic blood pressure $(\mathrm{DBP}) \geq 90 \mathrm{mmHg}$, and/or self-reported current treatment for hypertension with antihypertensive medication $[39,40]$. The diagnostic criteria of overweight and obesity were according to the Cooperative Meta-analysis Group of China Obesity Task Force. Normal weight, overweight and obesity were defined as a BMI $<24,24-28,>28 \mathrm{~kg} / \mathrm{m}^{2}$; respectively [41].

\section{Statistical analysis}

The statistical analyses were done with the statistical software package SPSS16.0 (SPSS Inc., Chicago, Illinois). Quantitative variables were expressed as mean \pm standard deviation (serum TG levels were presented as medians and interquartile ranges). Qualitative variables were expressed as percentages. Allele frequency was determined via direct counting, and the standard goodness-of-fit test was used to test the Handy-Weinberg equilibrium. Difference in genotype distribution between the groups was obtained using the chi-square test. The difference in general characteristics between two ethnic groups was tested by the Student's unpaired $t$-test. The association of genotypes and serum lipid parameters was tested by analysis of covariance (ANOVA). Age, sex, BMI, blood pressure, alcohol consumption, and cigarette smoking were included in the statistical models as covariates. Multiple linear regression analyses adjusted for age, sex, BMI, blood pressure, alcohol consumption, and cigarette smoking were also performed to assess the association of serum lipid levels with genotypes $(\mathrm{AA}=1, \mathrm{AG}=2, \mathrm{GG}=3$; or $\mathrm{AA}=1$, AG/GG $=2$ ) and several environment factors. A $P$ value of less than 0.05 was considered statistically significant.

\section{Results}

\section{General characteristics and serum lipid levels}

Table 1 shows the general characteristics and serum lipid levels of the study populations. The levels of $A p o B$ and the percentage of subjects who consumed alcohol were higher but the levels of body weight, BMI, and diastolic blood pressure were lower in Mulao than in Han $(P<0.05-0.001)$. There were no significant differences in the levels of age, systolic blood pressure, pulse pressure, blood glucose, TC, TG, HDL-C, LDL-C, ApoAI; and the ratio of ApoAI to $A p o B$ and male to female; the percentage of subjects who smoked cigarette between the two ethnic groups $(P>0.05$ for all $)$.

Table I. Comparison of demographics, lifestyle and serum lipid levels between the Mulao and Han populations

\begin{tabular}{|c|c|c|c|c|}
\hline Parameter & Mulao & Han & $t\left(\chi^{2}\right)$ & $P$ \\
\hline Number & 721 & 727 & - & - \\
\hline Male/female & $336 / 385$ & $346 / 381$ & 0.143 & 0.706 \\
\hline Age (years) & $52.31 \pm 14.50$ & $51.94 \pm 12.52$ & 0.514 & 0.608 \\
\hline Height $(\mathrm{cm})$ & $155.58 \pm 7.97$ & $154.99 \pm 7.65$ & 1.428 & 0.154 \\
\hline Weight (kg) & $53.04 \pm 9.33$ & $54.45 \pm 8.96$ & -2.930 & 0.003 \\
\hline $\begin{array}{l}\text { Body mass index } \\
\left(\mathrm{kg} / \mathrm{m}^{2}\right)\end{array}$ & $21.85 \pm 3.07$ & $22.64 \pm 3.22$ & -4.736 & $<0.001$ \\
\hline Waist circumference & $75.13 \pm 8.87$ & $75.41 \pm 7.90$ & -0.647 & 0.518 \\
\hline \multicolumn{5}{|l|}{$\begin{array}{l}\text { Cigarette smoking }[n \\
(\%)]\end{array}$} \\
\hline Nonsmoker & $537(74.5)$ & $530(72.9)$ & & \\
\hline$\leq 20$ cigarettes/day & $154(21.4)$ & $150(20.6)$ & & \\
\hline$>20$ cigarettes/day & $30(4.1)$ & $47(6.5)$ & 3.827 & 0.148 \\
\hline \multicolumn{5}{|l|}{$\begin{array}{l}\text { Alcohol consumption } \\
{[n(\%)]}\end{array}$} \\
\hline Nondrinker & $537(74.5)$ & $538(78.5)$ & & \\
\hline$\leq 25 \mathrm{~g} /$ day & $61(8.5)$ & $74(9.2)$ & & \\
\hline$>25 \mathrm{~g} /$ day & $123(17.1)$ & 115 (12.3) & 6.753 & 0.034 \\
\hline $\begin{array}{l}\text { Systolic blood pressure } \\
(\mathrm{mmHg})\end{array}$ & $129.40 \pm 21.69$ & $130.31 \pm 18.52$ & -0.860 & 0.390 \\
\hline $\begin{array}{l}\text { Diastolic blood } \\
\text { pressure }(\mathrm{mmHg})\end{array}$ & $81.23 \pm 11.67$ & $82.86 \pm 10.94$ & -2.743 & 0.006 \\
\hline $\begin{array}{l}\text { Pulse pressure } \\
(\mathrm{mmHg})\end{array}$ & $48.17 \pm 16.09$ & $47.45 \pm 13.77$ & 0.914 & 0.361 \\
\hline $\begin{array}{l}\text { Blood glucose } \\
(\mathrm{mmol} / \mathrm{L})\end{array}$ & $5.99 \pm 1.61$ & $6.15 \pm 1.81$ & -1.877 & 0.061 \\
\hline $\begin{array}{l}\text { Total cholesterol } \\
(\mathrm{mmol} / \mathrm{L})\end{array}$ & $5.03 \pm 1.35$ & $5.10 \pm 1.16$ & -1.027 & 0.305 \\
\hline Triglyceride (mmol/L) & $1.07(0.82)$ & $1.09(0.89)$ & -1.333 & 0.182 \\
\hline HDL-C (mmol/L) & $1.75 \pm 0.46$ & $1.75 \pm 0.58$ & 0.024 & 0.981 \\
\hline LDL-C (mmol/L) & $2.92 \pm 0.90$ & $2.91 \pm 0.87$ & 0.079 & 0.937 \\
\hline $\begin{array}{l}\text { Apolipoprotein (Apo) } \\
\text { AI (g/L) }\end{array}$ & $1.32 \pm 0.41$ & $1.35 \pm 0.26$ & -1.666 & 0.096 \\
\hline $\operatorname{ApoB}(g / L)$ & $0.98 \pm 0.57$ & $0.87 \pm 0.21$ & 4.792 & $<0.001$ \\
\hline ApoAI/ApoB & $1.62 \pm 1.01$ & $1.64 \pm 0.51$ & -0.432 & 0.666 \\
\hline
\end{tabular}

HDL-C, high-density lipoprotein cholesterol; LDL-C, low-density lipoprotein cholesterol. The value of triglyceride was presented as median (interquartile range), the difference between the two ethnic groups was determined by the Wilcoxon-Mann-Whitney test.

\section{Electrophoresis and genotypes}

After the genomic DNA of the samples was amplified by PCR and imaged by $2.0 \%$ agarose gel electrophoresis, the PCR products of $225 \mathrm{bp}$ nucleotide sequences could be seen in the samples (Supplementary Material: Figure S1). The genotypes identified were named according to the presence (A allele) or absence ( $G$ allele) of the enzyme restriction sites. Thus, AA genotype is heterozygote for the presence of the site (bands at 176-, 30- and 19-bp), AG genotype is heterozygote for the absence and presence of the site 
(bands at 206-, 176-, 30- and 19-bp), and the GG genotype is homozygote for the absence of the site (bands at 206- and 19-bp; Supplementary Material: Figure S2). The 30-bp and 19-bp fragments were invisible in the gel owing to their fast migration speed. The genotypes of the rs7395662 SNP were followed by the Hardy-Weinberg equilibrium.

\section{Nucleotide sequences}

The results were shown as AA, AG and GG genotypes of the rs7395662 SNP by PCR-RFLP, the genotypes were also confirmed by sequencing (Supplementary Material: Figure S3); respectively.

\section{Genotypic and allelic frequencies}

The genotypic and allelic frequencies of the rs7395662 SNP in the both ethnic groups are shown in Table 2. For the Han population, the allelic frequencies of $A$ and $G$ were $59.8 \%$ and $40.2 \%$ in males, and $53.1 \%$ and $46.9 \%$ in females $(P<0.05)$; respectively. The frequencies of AA, AG and GG genotypes were $36.4 \%, 46.8 \%$ and $16.8 \%$ in males, and $30.2 \%, 45.9 \%$ and $23.9 \%$ in females $(P<0.05)$; respectively. They are both in Hardy Weinberg Equilibrium $(P=0.780466$ for Mulao, $P=0.119036$ for Han). There were no significant differences in the allelic and genotypic frequencies between Mulao and Han, or between Mulao males and females.

\section{Genotypes and serum lipid levels}

As shown in Table 3, the levels of LDL-C and ApoB in Mulao females but not males were different among the genotypes $(P<0.05)$, the $G$ allele carriers had higher LDL-C and ApoB levels than the G allele non-carriers.

The levels of TC, TG, LDL-C and ApoB in Han males and TC, TG and HDL-C in Han females were different among the genotypes $(P<0.05-0.01)$, the subjects with GG genotype in Han males had higher TC, TG, and ApoB and lower LDL-C levels than the subjects with AA or AG genotype, and the $G$ allele carriers in Han females had lower TC and HDL-C levels than the $G$ allele non-carriers. The subjects with GG genotype in Han females also had higher TG levels that the subjects with AG genotype.

\section{Risk factors for lipid parameters}

The correlation between the genotypes of rs7395662 SNP and serum lipid parameters in Mulao and Han is shown in Table 4. The levels of LDL-C and ApoB in Mulao females were correlated with the genotypes ( $P<0.05$ for each). The levels of HDL-C and ApoAI in Han males and HDL-C in Han females were correlated with genotypes $(P<0.05-0.001)$.

Serum lipid parameters were also correlated with several environmental factors such as age, gender, height, weight, BMI, waist circumference, alcohol consumption, cigarette smoking, blood pressure and blood glucose in both ethnic groups $(P<0.05-0.001$; Table 5).

Table 2. Comparison of the genotypic and allelic frequencies of FOLHI rs7395662 SBNP between the Mulao and Han populations [ $n$ (\%)]

\begin{tabular}{|c|c|c|c|c|c|c|}
\hline \multirow[t]{2}{*}{ Group } & \multirow[t]{2}{*}{$n$} & \multicolumn{3}{|l|}{ Genotype } & \multicolumn{2}{|l|}{ Allele } \\
\hline & & $\mathrm{AA}$ & AG & GG & A & G \\
\hline Mulao & 721 & $221(30.6)$ & $353(49.0)$ & $147(20.4)$ & 795 (55.1) & 647 (44.9) \\
\hline Han & 727 & 241 (33.1) & 337 (46.4) & 149 (20.5) & $819(56.3)$ & 635 (43.7) \\
\hline$\chi^{2}$ & - & 1.225 & & & 0.419 & \\
\hline$P$ & - & 0.542 & & & 0.517 & \\
\hline \multicolumn{7}{|l|}{ Mulao } \\
\hline Male & 336 & $104(31.0)$ & $169(50.3)$ & 63 (18.8) & 377 (56.1) & $295(43.9)$ \\
\hline Female & 385 & $117(30.4)$ & $184(47.8)$ & $84(21.8)$ & $418(54.3)$ & $352(45.7)$ \\
\hline$x^{2}$ & - & 1.077 & & & 0.478 & \\
\hline$P$ & - & 0.584 & & & 0.489 & \\
\hline \multicolumn{7}{|l|}{ Han } \\
\hline Male & 346 & $126(36.4)$ & $162(46.8)$ & $58(16.8)$ & 414 (59.8) & $278(40.2)$ \\
\hline Female & 381 & 115 (30.2) & 175 (45.9) & 91 (23.9) & 405 (53.1) & 357 (46.9) \\
\hline$x^{2}$ & - & 6.643 & & & 6.572 & \\
\hline$P$ & - & 0.036 & & & 0.010 & \\
\hline
\end{tabular}


Table 3. The genotypes of rs7395662 SNP and serum lipid levels between the Mulao and Han populations

\begin{tabular}{|c|c|c|c|c|c|c|c|c|}
\hline Genotype & $n$ & $\begin{array}{l}\mathrm{TC} \\
(\mathrm{mmol} / \mathrm{L})\end{array}$ & $\begin{array}{l}\mathrm{TG} \\
(\mathrm{mmol} / \mathrm{L})\end{array}$ & $\begin{array}{l}\text { HDL-C } \\
(\mathrm{mmol} / \mathrm{L})\end{array}$ & $\begin{array}{l}\text { LDL-C } \\
(\mathrm{mmol} / \mathrm{L})\end{array}$ & $\begin{array}{l}\text { ApoAI } \\
(\mathrm{g} / \mathrm{L})\end{array}$ & $\begin{array}{l}\text { ApoB } \\
(g / L)\end{array}$ & $\begin{array}{l}\text { ApoAI/ } \\
\text { ApoB }\end{array}$ \\
\hline \multicolumn{9}{|l|}{ Mulao } \\
\hline $\mathrm{AA}$ & 221 & $4.96 \pm 1.11$ & $1.01(0.73)$ & $1.80 \pm 0.51$ & $2.86 \pm 0.85$ & $1.33 \pm 0.41$ & $0.92 \pm 0.52$ & $1.69 \pm 0.75$ \\
\hline$A G$ & 353 & $5.01 \pm 1.26$ & $1.10(0.86)$ & $1.72 \pm 0.44$ & $2.89 \pm 0.88$ & $1.31 \pm 0.41$ & $0.99 \pm 0.60$ & $1.64 \pm 1.05$ \\
\hline GG & 147 & $5.16 \pm 1.79$ & $1.17(0.75)$ & $1.72 \pm 0.43$ & $3.07 \pm 1.02$ & $1.33 \pm 0.38$ & $1.04 \pm 0.57$ & $1.49 \pm 0.64$ \\
\hline$F$ & - & 1.608 & 5.061 & 2.079 & 2.653 & 0.199 & 2.104 & 1.664 \\
\hline$P$ & - & 0.344 & 0.080 & 0.126 & 0.071 & 0.820 & 0.123 & 0.190 \\
\hline \multicolumn{9}{|l|}{ Han } \\
\hline $\mathrm{AA}$ & 241 & $5.21 \pm 1.16$ & $1.14(1.03)$ & $1.82 \pm 0.80$ & $3.05 \pm 0.90$ & $1.39 \pm 0.27$ & $0.90 \pm 0.23$ & $1.67 \pm 0.95$ \\
\hline AG & 337 & $4.96 \pm 1.01$ & $0.97(0.79)$ & $1.72 \pm 0.42$ & $2.86 \pm 0.84$ & $1.33 \pm 0.26$ & $0.84 \pm 0.19$ & $1.59 \pm 0.61$ \\
\hline GG & 149 & $5.25 \pm 1.40$ & $1.28(0.72)$ & $1.68 \pm 0.42$ & $2.82 \pm 0.90$ & $1.35 \pm 0.25$ & $0.89 \pm 0.21$ & $1.59 \pm 0.48$ \\
\hline$F$ & - & 5.013 & 15.918 & 3.283 & 4.577 & 2.945 & 6.654 & 1.123 \\
\hline$P$ & - & 0.007 & $<0.001$ & 0.038 & 0.011 & 0.063 & 0.001 & 0.326 \\
\hline \multicolumn{9}{|c|}{ Mulao/male } \\
\hline $\mathrm{AA}$ & 104 & $5.08 \pm 1.48$ & $0.99(0.90)$ & $1.80 \pm 0.58$ & $2.90 \pm 0.82$ & $1.33 \pm 0.45$ & $0.98 \pm 0.59$ & $1.60 \pm 0.80$ \\
\hline AG & 169 & $5.13 \pm 1.38$ & $1.29(0.97)$ & $1.72 \pm 0.46$ & $2.85 \pm 0.87$ & $1.33 \pm 0.43$ & $1.06 \pm 0.43$ & $1.49 \pm 0.65$ \\
\hline GG & 63 & $5.21 \pm 2.17$ & $1.33(0.96)$ & $1.70 \pm 0.45$ & $2.91 \pm 0.95$ & $1.36 \pm 0.43$ & $1.04 \pm 0.57$ & $1.51 \pm 0.65$ \\
\hline$F$ & - & 0.162 & 5.141 & 1.143 & 0.130 & 0.126 & 0.509 & 0.091 \\
\hline$P$ & - & 0.850 & 0.077 & 0.320 & 0.878 & 0.881 & 0.601 & 0.407 \\
\hline \multicolumn{9}{|c|}{ Mulao/female } \\
\hline $\mathrm{AA}$ & 117 & $4.86 \pm 1.12$ & $1.03(0.64)$ & $1.80 \pm 0.41$ & $2.83 \pm 0.87$ & $1.34 \pm 0.36$ & $0.86 \pm 0.44$ & $1.76 \pm 0.70$ \\
\hline AG & 184 & $4.91 \pm 1.13$ & $1.00(0.69)$ & $1.73 \pm 0.43$ & $2.92 \pm 0.88$ & $1.30 \pm 0.40$ & $0.92 \pm 0.50$ & $1.78 \pm 1.10$ \\
\hline GG & 84 & $5.13 \pm 1.46$ & $1.06(0.67)$ & $1.74 \pm 0.41$ & $3.18 \pm 1.06$ & $1.31 \pm 0.34$ & $1.05 \pm 0.57$ & $1.49 \pm 0.64$ \\
\hline$F$ & - & 1.374 & 1.368 & 0.986 & 3.749 & 0.356 & 3.340 & 1.845 \\
\hline$P$ & - & 0.254 & 0.505 & 0.374 & 0.024 & 0.701 & 0.036 & 0.159 \\
\hline \multicolumn{9}{|l|}{ Han/male } \\
\hline AA & 126 & $5.27 \pm 1.32$ & $1.22(1.10)$ & $1.72 \pm 0.42$ & $3.11 \pm 0.96$ & $1.43 \pm 0.31$ & $0.95 \pm 0.25$ & $1.61 \pm 0.57$ \\
\hline AG & 162 & $5.16 \pm 0.70$ & $1.15(0.95)$ & $1.70 \pm 0.42$ & $2.90 \pm 0.70$ & $1.37 \pm 0.26$ & $0.88 \pm 0.15$ & $1.60 \pm 0.45$ \\
\hline GG & 58 & $5.83 \pm 1.86$ & $1.48(1.00)$ & $1.62 \pm 0.44$ & $2.78 \pm 1.01$ & $1.35 \pm 0.24$ & $0.99 \pm 0.23$ & $1.44 \pm 0.43$ \\
\hline$F$ & - & 6.601 & 6.295 & 1.090 & 3.333 & 2.251 & 7.326 & 2.713 \\
\hline$P$ & - & 0.002 & 0.043 & 0.337 & 0.037 & 0.107 & 0.001 & 0.067 \\
\hline \multicolumn{9}{|c|}{ Han/female } \\
\hline $\mathrm{AA}$ & 115 & $5.13 \pm 0.95$ & $1.07(0.88)$ & $1.96 \pm 1.06$ & $2.99 \pm 0.82$ & $1.34 \pm 0.20$ & $0.85 \pm 0.21$ & $1.69 \pm 0.50$ \\
\hline$A G$ & 175 & $4.76 \pm 1.20$ & $0.87(0.59)$ & $1.74 \pm 0.43$ & $2.82 \pm 0.94$ & $1.30 \pm 0.26$ & $0.80 \pm 0.21$ & $1.73 \pm 0.53$ \\
\hline GG & 91 & $4.89 \pm 0.83$ & $1.11(0.82)$ & $1.73 \pm 0.41$ & $2.85 \pm 0.76$ & $1.35 \pm 0.25$ & $0.82 \pm 0.16$ & $1.69 \pm 0.49$ \\
\hline$F$ & - & 4.831 & 13.283 & 3.578 & 1.469 & 1.318 & 2.143 & 0.252 \\
\hline$P$ & - & 0.013 & 0.001 & 0.029 & 0.231 & 0.269 & 0.119 & 0.778 \\
\hline
\end{tabular}

TC, total cholesterol; TG, triglyceride; HDL-C, high-density lipoprotein cholesterol; LDL-C, low-density lipoprotein cholesterol; ApoAI, apolipoprotein AI; ApoB, apolipoprotein B; ApoAI/ApoB, the ratio of apolipoprotein AI to apolipoprotein B. The values of TG were presented as median (interquartile range). The difference among the genotypes was determined by the Kruskal-Wallis test.

Table 4. Correlation between the genotypes of rs7395662 SNP and serum lipid parameters in the Mulao and Han populations

\begin{tabular}{|c|c|c|c|c|c|c|}
\hline Lipid parameter & Risk factor & $\begin{array}{l}\text { Unstandardized coeffi- } \\
\text { cient }\end{array}$ & Std. error & $\begin{array}{l}\text { Standardized } \\
\text { coefficient }\end{array}$ & $t$ & $P$ \\
\hline \multicolumn{7}{|l|}{ Mulao and Han } \\
\hline HDL-C & Genotype & 0.063 & 0.019 & 0.086 & 3.371 & 0.001 \\
\hline ApoAI/ApoB & Genotype & 0.073 & 0.029 & 0.066 & 2.568 & 0.010 \\
\hline \multicolumn{7}{|l|}{ Mulao } \\
\hline ApoB & Genotype & -0.063 & 0.030 & -0.078 & -2.129 & 0.034 \\
\hline \multicolumn{7}{|l|}{ Han Chinese } \\
\hline HDL-C & Genotype & 0.103 & 0.030 & 0.126 & 3.392 & 0.001 \\
\hline ApoAI & Genotype & 0.034 & 0.013 & 0.094 & 2.720 & 0.007 \\
\hline ApoAI/ApoB & Genotype & 0.079 & 0.023 & 0.116 & 3.424 & 0.001 \\
\hline \multicolumn{7}{|l|}{ Mulao/Female } \\
\hline LDL-C & Genotype & -0.146 & 0.064 & -0.113 & -2.265 & 0.024 \\
\hline ApoB & Genotype & -0.087 & 0.035 & -0.125 & -2.524 & 0.012 \\
\hline \multicolumn{7}{|l|}{ Han/Male } \\
\hline HDL-C & Genotype & 0.078 & 0.032 & 0.126 & 2.451 & 0.015 \\
\hline
\end{tabular}




\begin{tabular}{|c|c|c|c|c|c|c|}
\hline ApoAI & Genotype & 0.071 & 0.020 & 0.174 & 3.613 & $<0.001$ \\
\hline \multicolumn{7}{|c|}{ Han/Female } \\
\hline HDL-C & Genotype & 0.129 & 0.050 & 0.135 & 2.591 & 0.010 \\
\hline
\end{tabular}

Table 5. Correlation between environmental factors and serum lipid parameters in the Mulao and Han populations

\begin{tabular}{|c|c|c|c|c|c|c|}
\hline Lipid parameter & Risk factor & $\begin{array}{l}\text { Unstandardized } \\
\text { coefficient }\end{array}$ & Std. error & $\begin{array}{l}\text { Standardized } \\
\text { coefficient }\end{array}$ & $t$ & $P$ \\
\hline \multicolumn{7}{|l|}{ Mulao and Han } \\
\hline \multirow[t]{5}{*}{$\mathrm{TC}$} & Age & 0.011 & 0.002 & 0.118 & 4.512 & $<0.001$ \\
\hline & Diastolic blood pressure & 0.010 & 0.003 & 0.090 & 3.314 & 0.001 \\
\hline & Cigarette smoking & 0.184 & 0.064 & 0.082 & 2.857 & 0.004 \\
\hline & Alcohol consumption & 0.142 & 0.048 & 0.086 & 2.968 & 0.003 \\
\hline & BMI & 0.045 & 0.010 & 0.114 & 4.372 & $<0.001$ \\
\hline \multirow[t]{4}{*}{ TG } & Diastolic blood pressure & 0.019 & 0.006 & 0.087 & 3.360 & 0.001 \\
\hline & Cigarette smoking & 0.854 & 0.116 & 0.191 & 7.501 & $<0.001$ \\
\hline & Weight & 0.034 & 0.007 & 0.123 & 4.605 & $<0.001$ \\
\hline & Blood glucose & 0.147 & 0.036 & 0.103 & 4.110 & $<0.001$ \\
\hline \multirow[t]{2}{*}{ HDL-C } & Weight & -0.013 & 0.002 & -0.230 & -8.696 & $<0.001$ \\
\hline & Cigarette smoking & 0.099 & 0.025 & 0.106 & 4.018 & 0.001 \\
\hline \multirow[t]{4}{*}{ LDL-C } & Gender & -0.120 & 0.057 & -0.067 & -2.108 & 0.035 \\
\hline & Age & 0.010 & 0.002 & 0.159 & 6.250 & $<0.001$ \\
\hline & Cigarette smoking & -0.232 & 0.050 & -0.146 & -4.615 & $<0.001$ \\
\hline & BMI & 0.052 & 0.007 & 0.185 & 7.251 & $<0.001$ \\
\hline \multirow[t]{3}{*}{ ApoAI } & Gender & 0.057 & 0.025 & 0.083 & 2.242 & 0.025 \\
\hline & Cigarette smoking & 0.127 & 0.020 & 0.210 & 6.429 & $<0.001$ \\
\hline & Alcohol consumption & 0.048 & 0.014 & 0.108 & 3.412 & $<0.001$ \\
\hline \multirow{3}{*}{ ApoB } & Weight & 0.007 & 0.001 & 0.140 & 5.161 & $<0.001$ \\
\hline & Systolic blood pressure & 0.001 & 0.001 & 0.067 & 2.532 & 0.011 \\
\hline & Blood glucose & 0.022 & 0.006 & 0.091 & 3.486 & 0.001 \\
\hline \multirow[t]{4}{*}{ ApoAI/ApoB } & Gender & 0.242 & 0.051 & 0.151 & 4.706 & $<0.001$ \\
\hline & Age & -0.005 & 0.002 & -0.080 & -3.154 & 0.002 \\
\hline & Cigarette smoking & 0.173 & 0.045 & 0.122 & 3.814 & $<0.001$ \\
\hline & BMI & -0.049 & 0.006 & -0.194 & -7.568 & $<0.001$ \\
\hline \multicolumn{7}{|l|}{ Mulao } \\
\hline \multirow[t]{2}{*}{$\mathrm{TC}$} & BMI & 0.062 & 0.016 & 0.142 & 3.837 & $<0.001$ \\
\hline & Cigarette smoking & 0.250 & 0.093 & 0.100 & 2.703 & 0.007 \\
\hline \multirow[t]{2}{*}{ TG } & Weight & 0.043 & 0.009 & 0.180 & 4.785 & $<0.001$ \\
\hline & Cigarette smoking & 0.535 & 0.156 & 0.129 & 3.428 & 0.001 \\
\hline \multirow[t]{3}{*}{ HDL-C } & Height & -0.005 & 0.002 & -0.095 & -2.433 & 0.015 \\
\hline & Cigarette smoking & 0.135 & 0.034 & 0.156 & 4.013 & $<0.001$ \\
\hline & BMI & -0.040 & 0.005 & -0.263 & -7.319 & $<0.001$ \\
\hline \multirow[t]{2}{*}{ LDL-C } & Height & -0.009 & 0.004 & -0.078 & -2.120 & 0.034 \\
\hline & BMI & 0.049 & 0.011 & 0.168 & 4.553 & $<0.001$ \\
\hline \multirow[t]{2}{*}{ ApoAI } & Gender & 0.076 & 0.036 & 0.094 & 2.109 & 0.035 \\
\hline & Cigarette smoking & 0.161 & 0.034 & 0.214 & 4.794 & $<0.001$ \\
\hline \multirow[t]{2}{*}{ ApoB } & Weight & 0.009 & 0.002 & 0.152 & 4.154 & $<0.001$ \\
\hline & Blood glucose & 0.039 & 0.013 & 0.111 & 3.015 & 0.003 \\
\hline \multirow[t]{3}{*}{ ApoAI/ApoB } & Gender & 0.155 & 0.075 & 0.076 & 2.055 & 0.040 \\
\hline & BMI & -0.043 & 0.012 & -0.131 & -3.546 & $<0.001$ \\
\hline & Blood glucose & -0.043 & 0.012 & -0.085 & -2.308 & 0.021 \\
\hline \multicolumn{7}{|l|}{ Han Chinese } \\
\hline \multirow[t]{5}{*}{$\mathrm{TC}$} & Diastolic blood pressure & 0.022 & 0.004 & 0.211 & 5.829 & $<0.001$ \\
\hline & Gender & -0.275 & 0.126 & -0.118 & -2.190 & 0.029 \\
\hline & Waist circumference & 0.045 & 0.009 & 0.310 & 5.178 & $<0.001$ \\
\hline & BMI & 0.061 & 0.022 & 0.171 & 2.793 & 0.005 \\
\hline & Alcohol consumption & 0.206 & 0.068 & 0.130 & 3.049 & 0.002 \\
\hline TG & Waist circumference & 0.117 & 0.020 & 0.333 & 5.711 & $<0.001$ \\
\hline
\end{tabular}




\begin{tabular}{|c|c|c|c|c|c|c|}
\hline & Diastolic blood pressure & 0.032 & 0.009 & 0.127 & 3.572 & $<0.001$ \\
\hline & Cigarette smoking & 1.299 & 0.170 & 0.271 & 7.624 & $<0.001$ \\
\hline & Blood glucose & 0.296 & 0.061 & 0.169 & 4.829 & $<0.001$ \\
\hline \multirow[t]{3}{*}{ HDL-C } & Weight & -0.014 & 0.003 & -0.216 & -5.552 & $<0.001$ \\
\hline & Alcohol consumption & 0.062 & 0.031 & 0.078 & 2.022 & 0.044 \\
\hline & Blood glucose & -0.032 & 0.014 & -0.088 & -2.369 & 0.018 \\
\hline \multirow[t]{3}{*}{ LDL-C } & Gender & -0.455 & 0.094 & -0.258 & -4.834 & $<0.001$ \\
\hline & Waist circumference & 0.023 & 0.004 & 0.210 & 5.571 & $<0.001$ \\
\hline & Cigarette smoking & -0.347 & 0.071 & -0.230 & -4.886 & $<0.001$ \\
\hline \multirow[t]{3}{*}{ ApoAI } & Weight & -0.008 & 0.001 & -0.281 & -7.695 & $<0.001$ \\
\hline & Cigarette smoking & 0.067 & 0.018 & 0.150 & 3.786 & $<0.001$ \\
\hline & Alcohol consumption & 0.111 & 0.014 & 0.316 & 7.778 & $<0.001$ \\
\hline \multirow[t]{5}{*}{ ApoB } & Gender & -0.068 & 0.019 & -0.164 & -3.654 & $<0.001$ \\
\hline & Waist circumference & 0.009 & 0.001 & 0.351 & 10.019 & $<0.001$ \\
\hline & Diastolic blood pressure & 0.003 & 0.001 & 0.146 & 4.332 & $<0.001$ \\
\hline & Alcohol consumption & 0.036 & 0.011 & 0.128 & 3.321 & 0.001 \\
\hline & Blood glucose & 0.020 & 0.004 & 0.151 & 4.607 & $<0.001$ \\
\hline \multirow[t]{6}{*}{ ApoAI/ApoB } & Gender & 0.027 & 0.054 & 0.234 & 4.205 & $<0.001$ \\
\hline & Waist circunference & -0.011 & 0.003 & -0.186 & -3.673 & $<0.001$ \\
\hline & BMI & -0.038 & 0.007 & -0.252 & -5.123 & $<0.001$ \\
\hline & Cigarette smoking & 0.114 & 0.038 & 0.137 & 3.020 & 0.003 \\
\hline & Alcohol consumption & 0.092 & 0.027 & 0.140 & 3.384 & 0.001 \\
\hline & Blood glucose & -0.023 & 0.010 & -0.075 & -2.167 & 0.030 \\
\hline
\end{tabular}

TC, total cholesterol; TG, triglyceride; HDL-C, high-density lipoprotein cholesterol; LDL-C, low-density lipoprotein cholesterol; ApoAI, apolipoprotein AI; ApoB, apolipoprotein $\mathrm{B}$; ApoAI/ApoB, the ratio of apolipoprotein $\mathrm{AI}$ to apolipoprotein $\mathrm{B}$. The results are limited to associations with $P<0.05$ and corrected by bonferroni correction; the results with $P>0.05$ are not shown in the table.

\section{Discussion}

In the current study, we showed that serum ApoB levels were significantly higher in Mulao than in Han. Significant differences in the levels of TC, TG, HDL-C, LDL-C, ApoAI and the ratio of ApoAI to ApoB were not observed between the two ethnic groups. Proverbially, dislipidemia is one of the intermediate risk factors for CAD and it is a multifactorial and complicated origin which combined by genetic factors as well as environmental factors [6, 7]. Numerous studies have shown that serum lipid levels such as TG, HDL-C and LDL-C are intensively influenced by the genetic component of each individual. Hence, it may account for additional analytically challenges when studying non-European populations since most GWAS have been focused on populations of European descent exclusively.

Mulao nationality is one of the 11 minorities in Guangxi Zhuang Autonomous Region, which is a genetic feature distinctive nationality. Therefore, we surmised that the hereditary characteristic and some lipid-related gene polymorphisms in the Mulao population may be different from those in Han nationality.

The genotypic and allelic frequencies of the rs7395662 SNP have not been reported previously in Mulao and Han nationalities. The genotypic and allelic frequencies in previous GWAS are also inconsistent in different racial/ethnic groups. In the present study, we showed that the genotypic and allelic fre- quencies of the rs7395662 SNP in Han were different between males and females $(P<0.05$ for each), but there were no significant differences in the allelic and genotypic frequencies between Mulao and Han, or between Mulao males and females. The data in the International HapMap Project's data-base have suggested that the frequency of $\mathrm{G}$ allele was $62.7 \%$ in European, $58.9 \%$ in Han Chinese in Beijing, $48.9 \%$ in Japanese and $44.2 \%$ in Sub-Saharan African. As compared with other populations, we found that the frequency of $G$ allele in our study populations was lower than that in Han Chinese from Beijing, which may be caused by different sample sizes and Han Chinese from Beijing and Guangxi are different parts of Han. The results of the present study suggested that there may be a sex-specific difference in the rs7395662 SNP in our study populations.

The potential association of the rs7395662 SNP and serum/plasma lipid levels in humans has been investigated in several previous GWAS, but the results are inconsistent. Aulchenko et al. [14] showed that the rs7395662 SNP was significant association with HDL-C concentration $\left(P=6 \times 10^{-11}\right)$ in population of European descent. Chasman et al. [33] also found that this locus was associated with lipoprotein size measures and HDL-C. Furthermore, a study of copy number variants (CNVs) well-tagged by SNPs by Gamazon et al. [30] delivered that, the rs7395662 SNP was a replicated SNP associated with HDL-C which is tagging nearby CNV. As one of the newly identified lipid-associated loci, although the rs7395662 
SNP had been shown consistent evidence for association across European cohorts just as other loci, its role in lipid metabolism was less obvious [14, 31]. Aulchenko et al. [14] at the same time reported that the genetic effect is modest for the rs7395662 SNP in the variance of HDL-C. Unfortunately, these several previously cited studies all failed to expressly confirm the function of the MADD-FOLH1 and discover the direct evidence for a role in lipid metabolism of this SNP. Coincidentally, the Carotid Lesion Epidemiology And Risk (CLEAR) study [34] and a study of biochemical traits in Korčula Island [19] neither observed the significant association between this SNP with carotid artery disease and blood lipid profiles separately. Likewise, Weissglas-Volkov et al. [21] did not access the involvement in the increased susceptibility to dyslipidemia for the MADD-FOLH1 in Mexicans. In the present study, we showed that the levels of LDL-C and ApoB in Mulao females but not males were different among the genotypes, the $G$ allele carriers had higher LDL-C and ApoB levels than the G allele non-carriers. The levels of TC, TG, LDL-C and ApoB in Han males and TC, TG and HDL-C in Han females were different among the genotypes, the subjects with GG genotype in Han males had higher TC, TG, and ApoB and lower LDL-C levels than the subjects with AA or AG genotype, and the G allele carriers in Han females had lower TC and HDL-C levels than the $\mathrm{G}$ allele non-carriers. The subjects with GG genotype in Han females also had higher TG levels than the subjects with AG genotype. These findings suggested that there may be a sex-specific association of the rs7395662 SNP and serum lipid concentrations in our study populations.

Serum lipid levels have been demonstrated to be influenced by genetic factors and non-genetic factors, and the latter ones include environmental factors which are strongly related with serum lipid levels such as dietary patterns, lifestyle, obesity, physical inactivity, and hypertension [6,7]. Hence, different environmental modifiers that interact with genes influence serum lipid levels may become the major reason for inconsistency among studies conducted with lipid profiles [42, 43]. Moreover, owing to a variety of lifestyle and environments in our study populations resident in Guangxi, the effect of genetic variation may be further modified. In the current study, we simultaneously showed that serum lipid parameters were correlated with age, sex, height, weight, BMI, waist circumference, alcohol consumption, cigarette smoking, blood pressure and blood glucose in the both ethnic groups. These findings highlight the importance of the environmental factors in affecting serum lipid levels in our study populations. Although rice and corn are the staple food in the both ethnic groups, the people of Mulao nationality like to eat cold foods along with acidic and spicy dishes, therefore bean soy sauce and pickle vegetables become members of their most popular dishes. Meanwhile, they are fond of eating animal offals which contain abundant saturated fatty acid. It has been widely accepted that high-fat diets, particularly those contain rich saturated fatty acids, can raise the serum cholesterol concentrations as well as the risk of suffering cardiovascular disease [44].

\section{Conclusion}

We conclude from the present study that the genotypic and allelic frequencies of rs7395662 SNP in the MADD-FOLH1 are different between Han males and females. The association of the rs7395662 SNP and serum lipid levels is also different between Mulao and Han, or between males and females in the both ethnic groups. There may be a sex-specific association of the rs7395662 SNP and serum lipid levels in our study populations.

\section{Supplementary Material}

Figures S1-S3.

http://www.medsci.org/v10p1537s1.pdf

\section{Acknowledgements}

This study was supported by the National Natural Science Foundation of China (No: 30960130).

\section{Competing Interests}

The authors have declared that no competing interest exists.

\section{References}

1. Kuulasmaa K, Tunstall-Pedoe H, Dobson A, et al. Estimation of contribution of changes in classic risk factors to trends in coronary-event rates across the WHO MONICA Project populations. Lancet. 2000;355:675-87.

2. Sinnaeve PR, Donahue MP, Grass P, et al. Gene expression patterns in peripheral blood correlate with the extent of coronary artery disease. PLoS One. 2009;4:e7037.

3. Clarke R, Emberson JR, Parish S, et al. Cholesterol fractions and apolipoproteins as risk factors for heart disease mortality in older men. Arch Intern Med. 2007;167:1373-8.

4. Asselbergs FW, Guo Y, van Iperen EP, et al. Large-scale gene-centric meta-analysis across 32 studies identifies multiple lipid loci. Am J Hum Genet. 2012;91:823-38.

5. Teslovich TM, Musunuru K, Smith AV, et al. Biological, clinical and population relevance of 95 loci for blood lipids. Nature. 2010;466:707-13.

6. Ruixing Y, Qiming F, Dezhai Y, et al. Comparison of demography, diet, lifestyle, and serum lipid levels between the Guangxi Bai Ku Yao and Han populations. J Lipid Res. 2007;48:2673-81.

7. Ruixing Y, Yuming C, Shangling P, et al. Effects of demographic, dietary and other lifestyle factors on the prevalence of hyperlipidemia in Guangxi Hei Yi Zhuang and Han populations. Eur J Cardiovasc Prev Rehabil. 2006;13:977-84.

8. Elbers CC, Guo Y, Tragante V, et al. Gene-centric meta-analysis of lipid traits in African, East Asian and Hispanic populations. PLoS One. 2012;7:e50198.

9. Diabetes Genetics Initiative of Broad Institute of Harvard and MIT et al. Genome-wide association analysis identifies loci for type 2 diabetes and triglyceride levels. Science. 2007;316:1331-6. 
10. Kathiresan S, Melander O, Guiducci C, et al. Six new loci associated with blood low-density lipoprotein cholesterol, high-density lipoprotein cholesterol or triglycerides in humans. Nat Genet. 2008;40:189-97.

11. Wallace C, Newhouse SJ, Braund P, et al. Genome-wide association study identifies genes for biomarkers of cardiovascular disease: serum urate and dyslipidemia. Am J Hum Genet. 2008;82:139-49.

12. Willer CJ, Sanna S, Jackson AU, et al. Newly identified loci that influence lipid concentrations and risk of coronary artery disease. Nat Genet. 2008;40:161-9.

13. Heid IM, Boes E, Muller M, et al. Genome-wide association analysis of high-density lipoprotein cholesterol in the population-based KORA study sheds new light on intergenic regions. Circ Cardiovasc Genet. 2008;1:10-20.

14. Aulchenko YS, Ripatti S, Lindqvist I, et al. Loci influencing lipid levels and coronary heart disease risk in 16 European population cohorts. Nat Genet. 2009;41:47-55.

15. Kathiresan S, Willer CJ, Peloso GM, et al. Common variants at 30 loci contribute to polygenic dyslipidemia. Nat Genet. 2009;41:56-65.

16. Li X, Monda KL, Goring HH, et al. Genome-wide linkage scan for plasma high density lipoprotein cholesterol, apolipoprotein A-1 and triglyceride variation among American Indian populations: the Strong Heart Family Study. J Med Genet. 2009;46:472-9.

17. Chen R, Ren J, Li W, et al. A genome-wide scan for quantitative trait loci affecting serum glucose and lipids in a White Duroc $x$ Erhualian intercross F(2) population. Mamm Genome. 2009;20:386-92.

18. Zhang Z, Tao L, Chen Z, et al. Association of genetic loci with blood lipids in the Chinese population. PLoS One. 2011;6:e27305.

19. Zemunik T, Boban M, Lauc G, et al. Genome-wide association study of biochemical traits in Korcula Island, Croatia. Croat Med J. 2009;50:23-33.

20. Talmud PJ, Drenos F, Shah S, et al. Gene-centric association signals for lipids and apolipoproteins identified via the HumanCVD BeadChip. Am J Hum Genet. 2009;85:628-42.

21. Weissglas-Volkov D, Aguilar-Salinas CA, Sinsheimer JS, et al. Investigation of variants identified in caucasian genome-wide association studies for plasma high-density lipoprotein cholesterol and triglycerides levels in Mexican dyslipidemic study samples. Circ Cardiovasc Genet. 2010;3:31-8.

22. Johansen CT, Wang J, Lanktree MB, et al. Excess of rare variants in genes identified by genome-wide association study of hypertriglyceridemia. Nat Genet. 2010;42:684-7.

23. Waterworth DM, Ricketts SL, Song K, et al. Genetic variants influencing circulating lipid levels and risk of coronary artery disease. Arterioscler Thromb Vasc Biol. 2010;30:2264-76.

24. Keebler ME, Deo RC, Surti A, et al. Fine-mapping in African Americans of 8 recently discovered genetic loci for plasma lipids: the Jackson Heart Study. Circ Cardiovasc Genet. 2010;3:358-64.

25. Saleheen D, Soranzo N, Rasheed A, et al. Genetic determinants of major blood lipids in Pakistanis compared with Europeans. Circ Cardiovasc Genet. 2010;3: 348-57.

26. Kaess BM, Tomaszewski M, Braund PS, et al. Large-scale candidate gene analysis of HDL particle features. PLoS One. 2011;6:e14529.

27. Dumitrescu L, Carty CL, Taylor K, et al. Genetic determinants of lipid traits in diverse populations from the population architecture using genomics and epidemiology (PAGE) study. PLoS Genet. 2011;7:e1002138.

28. Lettre G, Palmer CD, Young T, et al. Genome-wide association study of coronary heart disease and its risk factors in 8,090 African Americans: the NHLBI CARe Project. PLoS Genet. 2011;7:e1001300.

29. Consortium IKC. Large-scale gene-centric analysis identifies novel variants for coronary artery disease. PLoS Genet. 2011;7:e1002260.

30. Gamazon ER, Nicolae DL, Cox NJ. A study of CNVs as trait-associated polymorphisms and as expression quantitative trait loci. PLoS Genet. 2011;7:e1001292.

31. Weissglas-Volkov D, Pajukanta P. Genetic causes of high and low serum HDL-cholesterol. J Lipid Res. 2010;51:2032-57.

32. Boes E, Coassin S, Kollerits B, et al. Genetic-epidemiological evidence on genes associated with HDL cholesterol levels: a systematic in-depth review. Exp Gerontol. 2009;44:136-60.

33. Chasman DI, Pare G, Mora S, et al. Forty-three loci associated with plasma lipoprotein size, concentration, and cholesterol content in genome-wide analysis. PLoS Genet. 2009;5:e1000730.

34. Ronald J, Rajagopalan R, Ranchalis JE, et al. Analysis of recently identified dyslipidemia alleles reveals two loci that contribute to risk for carotid artery disease. Lipids Health Dis. 2009; 8:52.

35. Franceschini N, Carty C, Buzkova P, et al. Association of genetic variants and incident coronary heart disease in multiethnic cohorts: the PAGE study. Circ Cardiovasc Genet. 2011;4:661-72.

36. Xu L, Deng QY, Li SF, et al. Genetic analysis of Mulao nationality using 15 short tandem repeats. Zhonghua Yi Xue Yi Chuan Xue Za Zhi. 2008;25:96-100.
37. Li Q, Yin RX, Yan TT, et al. Association of the GALNT2 gene polymorphisms and several environmental factors with serum lipid levels in the Mulao and Han populations. Lipids Health Dis. 2011;10:160.

38. An epidemiological study of cardiovascular and cardiopulmonary disease risk factors in four populations in the People's Republic of China. Baseline report from the P.R.C.-U.S.A. Collaborative Study. People's Republic of China--United States Cardiovascular and Cardiopulmonary Epidemiology Research Group. Circulation. 1992;85:1083-96.

39. Ruixing Y, Limei Y, Yuming C, et al. Prevalence, awareness, treatment, control and risk factors of hypertension in the Guangxi Hei Yi Zhuang and Han populations. Hypertens Res. 2006;29:423-32.

40. Ruixing Y, Weixiong L, Hanjun Y, et al. Diet, lifestyle, and blood pressure of the middle-aged and elderly in the Guangxi Bai Ku Yao and Han populations. Am J Hypertens. 2008;21:382-7.

41. Cooperative Meta-Analysis Group Of China Obesity Task Force. Predictive values of body mass index and waist circumference to risk factors of related diseases in Chinese adult population. Zhonghua Liu Xing Bing Xue Za Zhi. 2002;23:5-10.

42. Yin $\mathrm{RX}, \mathrm{Wu} \mathrm{DF}, \mathrm{Miao} \mathrm{L}$, et al. Several genetic polymorphisms interact with overweight/obesity to influence serum lipid levels. Cardiovasc Diabetol. 2012;11:123.

43. Yu-Poth S, Zhao G, Etherton T, et al. Effects of the National Cholesterol Education Program's Step I and Step II dietary intervention programs on cardiovascular disease risk factors: a meta-analysis. Am J Clin Nutr. 1999;69:632-46.

44. Gaziano JM, Buring JE, Breslow JL, et al. Moderate alcohol intake, increased levels of high-density lipoprotein and its subfractions, and decreased risk of myocardial infarction. N Engl J Med. 1993;329:1829-34. 